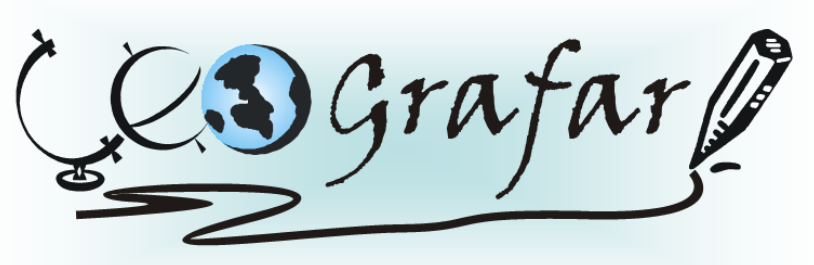

Revista Eletrônica do Programa de Pós-Graduação em Geografia - UFPR

\title{
A NECESSIDADE DE SE PLANEJAR O USO TURÍSTICO DO LAGO DO RESERVATÓRIO DA USINA SALTO OSÓRIO - PARANÁ: ATIVIDADES TURÍSTICAS DESENVOLVIDAS NO LOCAL E OS CONSEQUENTES IMPACTOS AMBIENTAIS
}

\author{
Sonia Mar Dos Santos Migliorini ${ }^{1}$ \\ Lucileyde Feitosa Sousa ${ }^{2}$ \\ Ana Solange Biesek ${ }^{3}$ \\ Carlos Ritter ${ }^{4}$
}

Resumo: Este artigo tem como objetivo analisar a oferta turística no reservatório da usina Salto Osório, localizado no Distrito Lagos do Iguaçu, no município de São Jorge do Oeste, região Sudoeste do estado do Paraná, bem como verificar os impactos ambientais causados pelo turismo no local. A metodologia utilizada se baseou na pesquisa bibliográfica sobre o tema proposto, aplicação de questionário aberto qualitativo com dez turistas e observação in loco. Constatou-se que o local é um dos principais atrativos turísticos do Sudoeste e atrai turistas de praticamente toda a Região que visitam o Lago a procura de lazer e repouso. Portanto, o turismo nesse local é uma das alternativas para o desenvolvimento do município São Jorge do Oeste e adjacentes. Contudo, a pesquisa também revelou que a atividade turística no local vem causando problemas ambientais, como a poluição do reservatório e a degradação da mata em torno de suas margens.

Palavras-chave: Oferta turística, impactos ambientais, reservatório hidrelétrico, Distrito Lagos do Iguaçu, município de São Jorge do Oeste - PR.

\section{THE NEED FOR TOURISM PLANNING AT THE RESERVOIR LAKE OF A HYDROPOWER PLANT IN SALTO OSÓRIO - PARANÁ STATE IN BRAZIL: TRAVEL ACTIVITIES UNDERTAKEN ON SITE AND ENVIRONMENTAL IMPACT}

ABSTRACT: This paper proposes to analyze the touristic offer at the Santo Osório Hydroelectric Reservoir, localized in Lagos do Iguaçu district, city of São Jorge do Oeste, region southwest of Paraná state, as well as verify the environmental impacts caused from the local tourism. The methodology used is based on the bibliography research about this topic, application of an open and qualitative questioner using ten tourists and in loco observation. The touristic potential at this city, like the meaning attractive at the Paraná southwest, that attract the tourists from different places and who visit the reservoir to look for leisure and relax. So, the local tourism is one alternative to the São Jorge do Oeste city develop and adjacent cities, but is necessary to consider the ambience's impacts caused by since the reservoir pollution until the ciliar bush destruction, what request a better touristic activity planning.

Keywords: touristic, ambience's impacts, hydroelectric reservoir, Lagos do Iguaçu District, São Jorge do Oeste City, Paraná state.

\footnotetext{
${ }^{1}$ Doutoranda em Geografia pela Universidade Federal do Paraná - UFPR; E-mail: soniamigliorini@bol.com.br

2 Doutoranda em Geografia pela Universidade Federal do Paraná - UFPR. E-mail: lucileyde@feitosa.org

3 Doutoranda em Geografia pela Universidade Federal do Paraná - UFPR; E-mail: ana.biesek@bol.com.br

${ }^{4}$ Doutorando em Geografia pela Universidade Federal do Paraná - UFPR; E-mail: carlos_ritter@hotmail.com
} 


\section{INTRODUÇÃO}

Nas últimas décadas, o turismo vem se tornando um dos setores mais marcantes do mundo contemporâneo e a sua importância ultrapassa o fator econômico, tornando-se também, um fenômeno político, social e cultural dos mais expressivos da sociedade atual. No contexto mundial, o turismo movimenta um grande volume de pessoas e de capitais, configurando-se materialmente de forma cada vez mais significativa. A indústria do turismo é a atividade que mais cresceu nos últimos dez anos no contexto econômico mundial, movimentando, conforme a Agência Nacional das Águas - ANA, "cerca de US\$ 3,5 trilhões anualmente e, apenas na última década, expandiu suas atividades em torno de 57\%" (2005, p.15).

Dessa forma, o turismo é um dos segmentos da economia que pode atender de forma rápida o desafio da geração de emprego e riqueza, especialmente nas regiões mais pobres, já que possui elevada capacidade de interferir nas desigualdades regionais, diminuindo-as, devido a natureza de suas atividades e na capacidade de atrair para as regiões menos desenvolvidas, detentoras de atrativos turísticos importantes, pessoas de maior poder aquisitivo residentes em centros desenvolvidos do Brasil e também do exterior.

Sob esta égide, dentro do setor de turismo brasileiro, uma das práticas que está em franca expansão é o turismo nos lagos de reservatórios de usinas hidrelétricas, como é o caso do lago do reservatório da Usina Salto Osório, no Paraná, objeto de estudo dessa pesquisa. Nesse local, o que se constata é que a atividade turística praticada não recebe um planejamento adequado, ocorrendo de forma desordenada e despreocupada, ou seja, não há uma preocupação em incrementar a atividade turística e, ao mesmo tempo, manter a integridade dos ecossistemas envolvidos.

Diante disso, os impactos causados pelo desenvolvimento do turismo decorrentes da falta de um planejamento podem provocar a degradação da paisagem e maior poluição dos recursos hídricos, o que resultaria em prejuízos para o espaço natural com propensão a degradação e, consequentemente, perda dos valores atrativos para o desenvolvimento da atividade turística, pois o aumento da poluição pela atividade turística poderá causar o afastamento dos próprios turistas. 
Daí a importância do planejar o desenvolvimento dessa atividade para fins de prevenir a elevação da poluição dos lagos e minimizar os impactos socioambientais.

Nesse sentido, este artigo tem como objetivo analisar a oferta turística no lago do reservatório da usina Salto Osório, denominado Lago do Iguaçu, localizado no Distrito Lagos do Iguaçu no município de São Jorge do Oeste, região Sudoeste do Paraná, bem como verificar os impactos ambientais causados pelo turismo nesse local, enfatizando a necessidade de melhor planejar o uso turístico do mesmo. A metodologia utilizada priorizou a pesquisa bibliográfica sobre o tema proposto, entrevistas abertas qualitativa com dez turistas. Como são entrevistas qualitativas, e não quantitativas, o número de entrevistados é bastante representativo para essa pesquisa. Além disso, também foram realizadas visitas no local para observação in loco e registro imagens do mesmo (fotografias), que reforçam os apontamentos feitos pelos entrevistados.

O artigo encontra-se dividido em sete seções: após a introdução, a primeira parte do artigo, apresenta-se uma breve abordagem sobre definição e importância econômica e social do turismo; na terceira parte, discute-se os termos oferta, atrativos e infraestrutura turística; em seguida, procurou-se realizar uma análise sobre o turismo e impactos ambientais nos reservatórios de hidrelétricas; na quinta e sexta parte, trata-se, respectivamente, da oferta turística no reservatório da usina salto Osório, município de são Jorge do oeste Paraná e dos impactos ambientais gerados pela atividade turística no referido reservatório; por fim, as considerações finais elencam os principais resultados alcançados na pesquisa.

\section{IMPORTÂNCIA ECONÔMICA E SOCIAL DO TURISMO}

A abordagem sobre a importância econômica e social do turismo se torna cada vez mais relevante nos estudos geográficos, uma vez que o turista está sempre procurando novos espaços.

Segundo Costa, Ribeiro e Tavares $(2004,02)$, os primeiros estudos onde se utilizou a expressão "Geografia do turismo" datam de 1905, quando os impactos começavam a ser observados sobre a natureza, muito embora naquele momento histórico as viagens ainda fossem elitizadas. Mas, segundo as referidas autoras, é 
somente a partir da década de 1960 que o estudo do turismo no âmbito da geografia se acentua, tendo em vista o desenvolvimento acelerado desse, marcado pela prosperidade econômica dos países centrais no pós Guerra.

Desta forma, no momento em que o turismo ganha amplitude em seus rendimentos, chegando a ultrapassar os ganhos dos maiores ramos da economia, ele deixou de ser desprezível para a geografia. Assim, a partir, da década de 1980, "a geografia do turismo é tratada como um dos aspectos da geografia dos tempos livres", e começa a ocorrer um processo de deslocamento da população em busca do aproveitamento desse tempo. "Os tipos de turismo diferiam simultaneamente pela forma de atividade turística e pelos grupos sociais afetadas". (COSTA, RIBEIRO e TAVARES, 2004, 02).

\begin{abstract}
Esse desenvolvimento, engendrou um dinamismo muito grande na produção do espaço social mundial caracterizando-se por raras áreas com poucas alterações ou mais comumente áreas com alto grau de deterioração que em geral se tornam estagnadas enquanto espaços turísticos, e/ou ainda, a transformação de tradicionais espaços turísticos que acabam perdendo sua função principal, até a produção de espaços totalmente artificiais onde a natureza não desempenha nenhum papel. (COSTA, RIBEIRO e TAVARES, 2004, 02).
\end{abstract}

Segundo as referidas autoras, "o turismo constitui um conjunto de equipamentos muito diversificados de empresas e de práticas cujos impactos sobre - meio ambiente diferem quantitativa e qualitativamente entre si e, por isso, necessitam ser avaliados isoladamente" (Idem). Além disso, a atividade turística para se implementar necessita se apropriar de um espaço para montar suas infraestruturas. É aqui que reside a essência dos estudos geográficos sobre o turismo, para analisar como ocorre essa apropriação do espaço e como o conjunto de equipamentos turísticos reordena o espaço das idéias, da circulação e da própria produção social.

Os estudos da geografia do turismo Segundo Rodrigues (1997, p.28), avançaram principalmente nos espaços receptores em virtude de serem nesses que ocorre a realização da produção e do consumo do fenômeno. Para a referida autora, o que dá significado à análise da atividade turística pela geografia, é a rápida criação e recriação do espaço para atender uma demanda específica do turismo. 
Seguindo uma linha de pensamento semelhante a essa, Mesquita afirma que para compreender o turismo deve-se partir das relações sociais com o lugar e dos homens entre si, na sociedade. Os lugares e paisagens são cada vez mais valorados e consumidos. "O lugar que era preservado, agora é consumido, com sua especificidade de bem ou "patrimônio" natural, cultural ou histórico" (2004, p.04). O aparecimento do fenômeno turístico, segundo a referida autora, reorganiza o lugar, redimensionando as esferas econômicas, políticas e socioculturais e afetando sobremaneira a sua organização espacial e é aí que reside a importância da ciência geográfica nos estudos sobre o turismo.

Quanto a definição de turismo, esse tem significado pluralista, a bibliografia é extensa e na maioria das vezes reflete o ponto de vista de quem a formula. No caso desta pesquisa, considerando a existência de muitas definições sobre o conceito de turismo, privilegia-se a definição da Organização Mundial do Turismo (OMT) a qual estabelece o turismo como sendo:

O fenômeno que ocorre das relações quando um ou mais indivíduos se transladam a um ou mais locais diferentes de sua residência habitual por um período maior que 24 horas e menor que 180 dias, sem participar dos mercados de trabalho e capital dos locais visitados, (OLIVEIRA, 2000, p. 31).

Complementa essa definição Oscar De La Torre quando define, por sua vez, o turismo como:

Um fenômeno social que consiste no deslocamento voluntário e temporário de indivíduos ou grupos de pessoas que, fundamentalmente por motivos de recreação, descanso, cultura ou saúde, se deslocam de seu lugar de residência habitual a outro, no qual não exercem nenhuma atividade lucrativa nem remunerada, gerando múltiplas inter-relações de importância social, econômica e cultural, (DE LA TORRE, 1994, p. 19).

Em princípio parece ser consenso que o turismo é uma atividade social e fundamentada no atendimento do lazer, nas atividades recreativas, atendendo, sobretudo, tanto os objetivos pessoais quanto coletivos dos sujeitos envolvidos. Através da atividade turística há o cultivar das relações sociais e afetivas que o homem mantém com o lugar, gerando significados nos contextos socioespaciais. 
De outro lado, Beltrão desenvolveu a seguinte definição de Turismo:

O Turismo é o conjunto de todas as atividades sociais, culturais, políticas, econômicas e naturais que envolvem pessoas se deslocando através dos mais diversos lugares de origem em busca de outros destinos desconhecidos ou não, com uma permanência temporária, (BELTRÃO,1999, p. 12).

Como pode ser observado, em todos os conceitos anteriores estão explicitas a idéia da viagem de ida, assim como o retorno do turista ao seu local de origem. Isto é, o turismo é caracterizado por dois aspectos: a viagem e o tempo de permanência no lugar, não menos de 24 horas e inferior a 180 dias. Diante disso, pode-se afirmar que no lago do reservatório da usina Salto Osório existe atividade turística sendo realizada por um grupo de pessoas que, atraído pela paisagem, pelo lugar, se lança ao desafio de visitá-lo, permanecendo mais do que 24 horas.

O objetivo principal de quem pratica 0 turismo é 0 descanso e 0 entretenimento. Com as conquistas trabalhistas, redução da jornada de trabalho, férias remuneradas, entre outros, o lazer e o turismo se tornaram mais abrangentes e viáveis. Logo, "O Turismo pode ser considerado uma necessidade social, quando a pessoa entende que deve viajar para obter determinado status e assim ser estimada pelo grupo". (BARRETTO, 1991, p.05), porém, o turismo só é praticado depois que todas as necessidades básicas foram atendidas.

A prática do turismo vem crescendo de maneira significativa em todo o mundo e ocupa hoje papel relevante na economia mundial. É um dos setores econômicos que mais crescem e atraem público cada vez mais diversificado. Movimenta o setor econômico numa sincronia com as várias empresas públicas e privadas que formam o setor, gerando produtos e serviços direcionados ao consumo do turista. Situandose, segundo Rodrigues (2001a, p.17), entre os três maiores produtos geradores de riqueza, produzindo sozinho $6 \%$ do produto interno bruto - PIB mundial. Segundo o referido autor, "o Turismo é, incontestavelmente, um fenômeno econômico, político, social e cultural dos mais expressivos das sociedades ditas pós-industriais" (2001, p. 17b). 
Para Dias e Aguiar o turismo, atualmente, é considerado a maior atividade econômica existente, superando setores tradicionais, tais como a indústria automobilística, a eletrônica e a petrolífera, tornando um grande gerador de postos de trabalho, além de um número incalculável de atividades correlatas. Além disso, o turismo tem efeito multiplicador, "o fluxo de divisas em direção à área de destino que desenvolve o turismo, não só constitui uma importante fonte de entrada para àquelas empresas ou pessoas vinculadas diretamente à atividade turística, como também beneficia os demais setores da economia" (2002, p.14).

Ao analisar os aspectos econômicos do turismo, sua importância, que engloba todos os setores de prestação de serviços e a relevância da atuação do poder público, conforme Beni, percebe-se que:

Do ponto de vista econômico, de fato, o Turismo representa uma atividade plurissetorial que necessita de coordenação e de planejamento de seu desenvolvimento, que só podem ser providos pelo poder público. Outra característica é sua relevante implicação social e cultural que não pode e não deve interessar apenas ao empreendedor, mas, acima de tudo, ao Governo, que representa a garantia dos interesses da coletividade, (BENI, 1998, p.98).

Não há dúvida de que a prática do turismo propicia muitos benefícios, mas sem um planejamento adequado e eficaz, de forma a reduzir os impactos no ambiente e na comunidade local, pode desencadear fatores negativos, tais como: a degradação e destruição dos recursos naturais e a perda da identidade da cultura local. Portanto, é necessário, além dos atrativos naturais em si, agregar serviços, corretamente planejados, que os complementem, de forma a satisfazer aos turistas e preservar o ambiente e comunidade local, minimizando os impactos negativos, maximizar os retornos econômicos e garantir sua sustentabilidade.

Os recursos naturais explorados pela atividade turística contribuem em impactar o meio ambiente, chegando até diminuir a qualidade de muitos atrativos; porém não significa que o turismo seja responsável por todo o dano ambiental.

Vale lembrar que as diferentes práticas econômicas são as que causam maiores danos aos ecossistemas turísticos por poluir as águas, os rios e mananciais com o lançamento de produtos químicos; expelindo na atmosfera gases poluentes; 
má destinação da coleta de lixo e a falta de conscientização da população local. (BENI, 1998, p.59)

É evidente que os impactos relativos ao meio ambiente precisam ser analisados com cuidado para o desenvolvimento de qualquer atividade, ainda mais no caso da atividade turística, cuja finalidade deve ser a de manter e controlar a qualidade ambiental e seu desenvolvimento sustentável. Sobre esse último conceito, Swarbrooke descreve:

Por "sustentável" geralmente queremos dizer "desenvolvimento que satisfaz nossas necessidades hoje, sem comprometer a capacidade das pessoas satisfazerem as suas no futuro". Trata-se, portanto, de uma perspectiva a um prazo mais longo que o usual ao tomarmos decisões, e envolve uma necessidade de intervenção e planejamento. $O$ conceito de sustentabilidade engloba claramente 0 meio ambiente, as pessoas e os sistemas econômicos, (SWARBROOKE, 2000, p.23).

Ruschmann considera o planejamento turístico como:

O processo que tem como finalidade ordenar as ações humanas sobre uma localidade turística, bem como direcionar a construção de equipamentos e facilidades, de forma adequada, evitando efeitos negativos nos recursos que possam destruir ou afetar sua atratividade. Constitui o instrumento fundamental na determinação e seleção das prioridades para a evolução harmoniosa da atividade turística, determinando suas dimensões ideais para que, a partir daí, se possa estimular, regular ou restringir sua evolução, (RUSCHMANN, 2006, p. 70).

A qualidade do planejamento e o desenvolvimento turístico irão determinar o sucesso e a longevidade de quaisquer destinações, como é o caso do objeto de estudo aqui referenciado, de maneira que tempo, esforço e recursos dedicados ao planejamento são investimentos essenciais para preservação e desenvolvimento do espaço turístico.

Considera-se que o turismo liga todos os lugares do mundo, sendo um fenômeno universal que contribui para o aumento da compreensão dos indivíduos de pertencerem a um todo e, ao mesmo tempo, incrementa a sua inteligência de 
pertencerem a um local determinado, pois, "com a presença do outro, ao se explicitarem as diferenças, se fortalecem a identidade cultural dos mesmos", (DIAS E AGUIAR, 2002, p.14 e 15).

Desta maneira, o turismo, ao mesmo tempo torna mais homogênea a cultura humana, destaca as diferenças, consolida a identidade cultural de um local, o que propicia a multiculturalidade. Assim, a intensificação do turismo poderá aumentar o respeito pelas diferenças, já que uma das principais motivações dos turistas é encontrar lugares e culturas diferentes de seu local de origem, o qual reforça a importância de se ter espaços turísticos bem planejados.

\section{OFERTA, ATRATIVOS E INFRAESTRUTURA TURÍSTICA}

De início, como oferta turística entende-se tudo o que o local dispõe e que pode ocupar o tempo dos turistas, englobando desde os atrativos à infraestrutura básica e turística. Alguns locais possuem potencial turístico, existindo objetos de interesse turístico Todavia, falta, geralmente, planejamento e organização em termos de melhoria na infraestrutura local, por isso não possuem visitação turística. Entretanto, os lugares com visitação turística oferecem, em geral, além dos atrativos turísticos, os quais motivam o deslocamento de grupos humanos para conhecê-los, uma infraestrutura que favorece a realização da atividade turística e cria condições para o desenvolvimento de um local turístico.

Destaca-se que quanto maior for a capacidade da localidade para investir na atividade turística que venha a produzir atividades que ocupem o tempo livre dos turistas, mais lucro irá auferir, e, consequentemente, mais a região ou o local turístico irá se desenvolver, pois o turista procura algo que ocupe seu tempo, de dia e à noite. Daí a importância das localidades turísticas conciliarem atrativos turísticos com a oferta de infraestrutura que possibilite o aproveitamento máximo do local pelo turista.

Por sua vez, os atrativos turísticos constituem o componente principal e mais importante do produto turístico. "É considerado como elemento básico para a determinação turística de uma localidade. No mais, torna-se o referencial do próprio local onde estão localizados ou se manifestam" (BAHL, 2004, p. 34-44). É através 
dos atrativos turísticos, como aponta o referido autor, que o turista seleciona o local de destino de sua viagem. E são os atrativos turísticos que geram a corrente turística até a localidade, daí a importância de adequá-los às visitações turísticas. Muitos atrativos apresentam-se de forma concreta, enquanto outros podem ser desenvolvidos e/ou utilizados para criar novos atrativos. Desta forma, os atrativos turísticos podem ser divididos basicamente em naturais e artificiais/culturais.

Quanto aos atrativos artificiais, ou seja, proveniente das manifestações humanas, segundo Barretto (1991, p.61), podem ser subdivididos em recursos culturais contemporâneos históricos, sem finalidade lucrativa, e que não são criados exclusivamente para o turismo (monumentos, museus, bibliotecas, obras de arte, etc.) e recursos turísticos culturais contemporâneos comerciais, criados para fazer parte do plano de desenvolvimento de uma área, tais como parque de diversões, balneários, cinemas, clubes de diversões, festas etc. Estes atrativos exigem certos cuidados no seu manuseio, já que podem ser descaracterizados com bastante facilidade. Ainda, podem ser utilizados como elemento diferenciador, devido a sua variedade e identificação junto ao processo cultural de uma localidade.

Em muitos lugares turísticos existem atrativos naturais e artificiais/culturais. No entanto, tanto um como o outro pode ser trabalhado isoladamente, ou seja, há locais turísticos que seus atrativos são os naturais; enquanto outros possuem como atrativos, os artificiais. No caso desta pesquisa o principal atrativo é o natural, não sendo desconsiderados àqueles artificiais.

No que ser refere aos atrativos turísticos naturais, esses, na concepção de Oliveira (2000, p.78), reúnem todos os componentes criados pela natureza que, por suas características, podem ser utilizados como atração turística: paisagem (atração única e por isso exige preservação), além de montanhas, praias e balneários, rios, lagos e lagoas, cânions e gargantas, cascatas, grutas, áreas de caça e pesca, costa litorânea, cachoeiras, parques e reservas de fauna e flora.

Nos atrativos naturais, como destaca Bahl (2004, p.34 e 35), a intervenção humana visa apenas o atendimento de algumas particularidades, tais como a adequação da infraestrutura para a visitação, utilização e melhor aproveitamento do local pelo turista. 
No que tange a infraestrutura turística, essa engloba todo o conjunto de bens e serviços que estão à disposição do turista como parte integrante, fundamental e acessória do fenômeno turístico. Da soma e o inter-relacionamento destes, segundo Barretto (1991, p.51/52), resultam a infraestrutura que uma cidade possui para o turismo.

A infraestrutura, como afirma Bahl (2004, p. 39-41), pode ser subdividida em duas classes: básica e turística; a primeira engloba todos os elementos que atendem as necessidades básicas das pessoas.

Já a infraestrutura turística, de acordo com o referido autor, refere-se àquelas instalações construídas quase que exclusivamente para o turismo, sem as quais ele não existe, tais como: agências de viagens e turismo; locadoras; estacionamento; alimentação (restaurantes, bares, lanchonetes etc.); hospedagem (hotéis, albergues de juventude, pousadas, áreas camping e outros); apoio turístico: (recepção, postos de informações e centros de eventos...); entidades de classe empresariais (agências de viagens, hotéis, organizadoras de eventos), e profissionais (guias, garçons, recepcionistas...); mão-de-obra especializada (centro de formação para qualificação, preparação, reciclagem, aperfeiçoamento).

A infraestrutura de uma localidade ou região turística possui forte influência sobre a demanda turística que visita este local. Daí a importância de ofertar ao turista uma infraestrutura mínima na qual proporcione o aproveitamento máximo dos atrativos turísticos de uma forma segura e confortável.

\section{TURISMO E IMPACTOS AMBIENTAIS NOS RESERVATÓRIOS DE HIDRELÉTRICAS}

Como descreve Vilas Boas (2006, p. 02), percebe-se, em alguns locais, que a disponibilidade de água diante dos diversos usos múltiplos já se apresenta frágil. No entanto, esse problema pode ser reduzido quando prevalece o uso sustentável desse recurso, imprescindível para a vida humana. Quando a situação de equilíbrio não ocorre, o governo e a sociedade terão que despender esforço para gerenciar a oferta e a demanda do recurso e estabelecer uma situação harmônica. 
No caso dos reservatórios hidrelétricos, nos últimos anos ocorreu uma ampliação do seu uso, além da geração de energia elétrica, passou a ser utilizado para diversas atividades ligadas à irrigação, pesca, lazer e turismo.

No intuito de se estabelecer condições mais propícias à obtenção de efeitos multiplicadores e de benefícios palpáveis para as populações locais, os usos múltiplos de reservatórios devem ser inseridos como fatores de desenvolvimento local e/ou regional, já que se tratam de empreendimentos vultosos que imprimem uma série de modificações nos seus contextos locais e/ou regionais. (VILAS BOAS, 2006, p.02).

O uso dos reservatórios hidrelétricos para fins de lazer e turismo vem ocorrendo intensamente em grande parte dos lagos de usinas hidrelétricas, é tem sido utilizado como uma forma de promover o desenvolvimento regional, como é a caso do reservatório Salto Osório, que passou a ser o grande atrativo turístico do Sudoeste do Paraná. Nesse sentido, é necessário propor formas "concretas de se promover um turismo ambientalmente sustentável, economicamente viável e socialmente justo, tendo como suporte, a dinâmica local e o planejamento participativo" (TARLOMBANI DA SILVEIRA, 2002, p.58). Para tanto, segundo o referido autor, o planejamento integrado do turismo deve trabalhar com as dimensões territorial, social, econômica e ambiental, integradas entre si.

Com a criação da Lei Federal no 9.433 de janeiro de 1997, voltada para a Política Nacional dos Recursos hídricos (PNRH), estabeleceu-se os usos múltiplos, garantindo o direito à igualdade para a utilização das águas a todos os setores. Esta Lei dispõe diversas vezes em seu texto, de forma direta ou indireta, sobre o aproveitamento turístico nos recursos hídricos, conforme os artigos $1^{\circ}$ do capítulo I, item IV que dispõe como um dos fundamentos da PNRH: "a gestão de recursos hídricos deve sempre proporcionar o uso múltiplo das águas" e do artigo $3^{\circ}$ do capítulo III, itens II, III e VI, respectivamente, tendo como diretrizes gerais a ação para implantação da PNRH:

A adequação da gestão de recursos hídricos às diversidades físicas, bióticas, demográficas, econômicas, sociais e culturais das diversas regiões do país; a integração da gestão de recursos hídricos com a 
gestão ambiental (ecoturismo); a integração da gestão das bacias hidrográficas com a dos sistemas estuarinos e zonas costeiras (turismo no litoral e em reservatórios e lagos interiores). (ANA, 2005, p.18).

Esses artigos da Lei deixam claro que os usos múltiplos, assim como a gestão desses recursos incluem o Turismo, podendo ser uma maneira de usufruí-lo, desde que se observem os princípios de conservação e de preservação.

Com a criação da Lei 9.433, o turismo em reservatórios de hidrelétricas se fortaleceu. As atividades de lazer e turismo ocorrem tanto dentro da água quanto nas margens dos reservatórios. Contudo, segundo Almeida, Viana e Alves, as atividades que ocorre nas margens do reservatório "estão diretamente vinculadas àquelas que se desenrolam dentro do mesmo". Para os referidos autores, as primeiras demandam maiores atenções que as últimas, uma vez que essas consomem mais tempo e geram impactos ambientais maiores, tais como a construção casas de veraneio, acampamento, pesca e piquenique. Na concepção desses autores, a construção de os abrigos e acampamentos provoca os maiores impactos, contudo, a construção de estradas, restaurantes, caminhos e demais facilidades capazes de alterar as condições naturais das margens e do meio ambiente, não podem ser ignoradas. "A construção de estradas e demais vias de acesso podem causar mudanças radicais na hidrologia das várzeas próximas ao reservatório, aumentar a erosão e difundir poluentes" (ALMEIDA, VIANA e ALVES, 2007, p.03).

Muitos desses impactos ocorrem por não haver um planejamento adequado das atividades turisticas. O que os dados revelam é o aumento cada maior do uso dos reservatórios para o turismo e pouco comprometimento com as conseqüências trazidas por ele. Pertille e Lanzer citam o estudo elaborado pela Eletrobrás sobre oitenta e nove represas, no qual se estimou:

Entre 14 possíveis usos das águas represadas para a geração hidrelétrica, os cinco primeiros têm a ver com a recreação: pesca amadora $(97,8 \%)$, acampamentos $(93,3 \%)$, caça $(80,9 \%)$, esportes aquáticos $(75,35 \%)$ e turismo organizado $(63,9 \%)$. A infraestrutura turística, nesses locais em sua maioria é composta por praias fluviais, pesca amadora, estrutura para prática de esportes náuticos e 
aquáticos, unidades de conservação nos arredores das represas que oferecem diversas opções de lazer como trilhas ecológicas e esportes radicais. (PERTILLE e LANZER, 2006, p.07).

No Brasil, conforme a ANA, a maioria da população costuma tirar férias em locais como praias, lagos, rios, estâncias hidrominerais, os quais têm recursos hídricos próprios para balneabilidade, sendo os mais procurados e entram em um processo de expansão da demanda relacionada ao turismo e das atividades econômicas ligadas ao setor terciário. Entretanto, "o que se vê na maior parte dessas áreas é a quase total despreocupação para manter a integridade do ecossistema envolvente, reforçando a necessidade de se estabelecer políticas locais para preservação da qualidade das águas utilizadas para o Turismo e Lazer" (ANA, 2005, p.15 e 16).

O aumento do número de hidrelétricas instaladas em um mesmo curso de água, como é o caso do rio Iguaçu que possui várias usinas geradoras de energia elétricas (Usina de Segredo, Foz do Areia, Salto Santiago, Salto Caxias, Salto Osório, sendo a última usina objeto desse estudo), associado ao ritmo de crescimento dos usos múltiplos dos reservatórios acentua o desequilíbrio do sistema natural, dificultando, desta forma, a auto-organização e renovação dos recursos naturais. Diante disso, como assinala Pertille e Lanzer (2006, p.08), são nítidas as conseqüências "desse desenvolvimento desordenado e de enfoque mais econômico que não contempla a preservação e o uso racional do meio ambiente" como a diminuição da qualidade de vida, devido à poluição e escassez das águas.

A atividade turística, na maioria dos reservatórios no Brasil, ainda ocorre de forma desordenada e despreocupada, ou seja, sem que haja um planejamento prévio que venha minimizar os impactos ambientais. Corroborando com está idéia a Agência Nacional das Águas - ANA descreve:

A poluição hídrica de represas, rios, lagos e cachoeiras representa um dos mais impactantes danos causados pelo crescimento descontrolado de atividades de turismo e recreação devido ao lançamento de esgotos e à geração de resíduos em embarcações de recreio que expelem gases, óleos e graxas, determinada pela ineficiência ou falta de coleta de lixo e pela falta de orientação dos próprios usuários. (ANA, 2005, p.34). 
Além dos fatores apontados pela ANA, há outros que agravam o impacto sobre o meio ambiente a exemplo da derrubada de mata ciliar, desordem espacial, ocupação intensiva das margens para a construção de empreendimentos turísticos (casas de veraneio, hotéis, restaurantes, clubes, praias artificiais e outros), assim como a geração de resíduos sólidos.

Como aponta a ANA (2005, p. 15/16), os danos ambientais provocados pelo desenvolvimento descontrolado do turismo nos reservatórios hidrelétricos, além de causar poluição dos recursos hídricos, degrada a paisagem, destrói a fauna e a flora, resulta na redução drástica de atividades de recreação e deflagra o afastamento de turistas.

Argumentam nesse sentido Pertille e Lanzer que "para alguns pesquisadores de Turismo, é mais fácil o turista tolerar a poluição em uma cidade continental que a poluição em praia, lago ou mar", tendo em vista que nesses locais o impacto visual é mais forte, (2006, p.08). Por isso, é inegável a importância da preservação da água dos reservatórios hidrelétricos. Mediante o planejamento das atividades turísticas, como destaca a ANA (2005, p.16 e 34), pode-se prevenir e minimizar os impactos socioambientais decorrentes da atividade recreacional, bem como a degradação dos recursos naturais existentes, principalmente dos recursos hídricos dos reservatórios.

Os múltiplos usos da água e sua apropriação por parte das atividades humanas, como argumenta Pertille e Lanzer (2006, p.08), permitem tanto a criação de valor quanto a perda, no caso da degradação devido o mau uso. No que se refere ao Turismo à criação de valor dar-se-á em função da criação da infraestrutura turística e a perda de valor ocorre quando a atividade turística promove a degradação da água e do entorno.

No entanto, a sustentabilidade da água dos reservatórios e do seu entorno pode ser alcançada no caso do uso do turismo pela adoção de práticas de prevenção e controle da degradação do meio ambiente, ambas associadas à garantia da atratividade da atividade turística perante seus participantes. 


\section{OFERTA TURÍSTICA NO RESERVATÓRIO DA USINA SALTO OSÓRIO, MUNICÍPIO DE SÃO JORGE DO OESTE PARANÁ}

A Formação do município de São Jorge do Oeste, cujo reservatório da Usina Salto Osório encontra-se localizado, de acordo com os dados da prefeitura municipal (2010, p.05) se deu, a partir da década de 1950, com a chegada de imigrantes europeus, italianos e alemães provenientes dos estados de Santa Catarina e do Rio Grande do Sul. Elevou-se à categoria de município no ano de 1963. Possui 379 km2 de área e 8.979 habitantes, conforme dados do Instituto Brasileiro de Geografia e Estatística - IBGE. A figura abaixo destaca a localização município no estado do Paraná.

FIGURA 01 - LOCALIZAÇÃO DO MUNICÍPIO DE SÃO JORGE DO OESTE PARANÁ

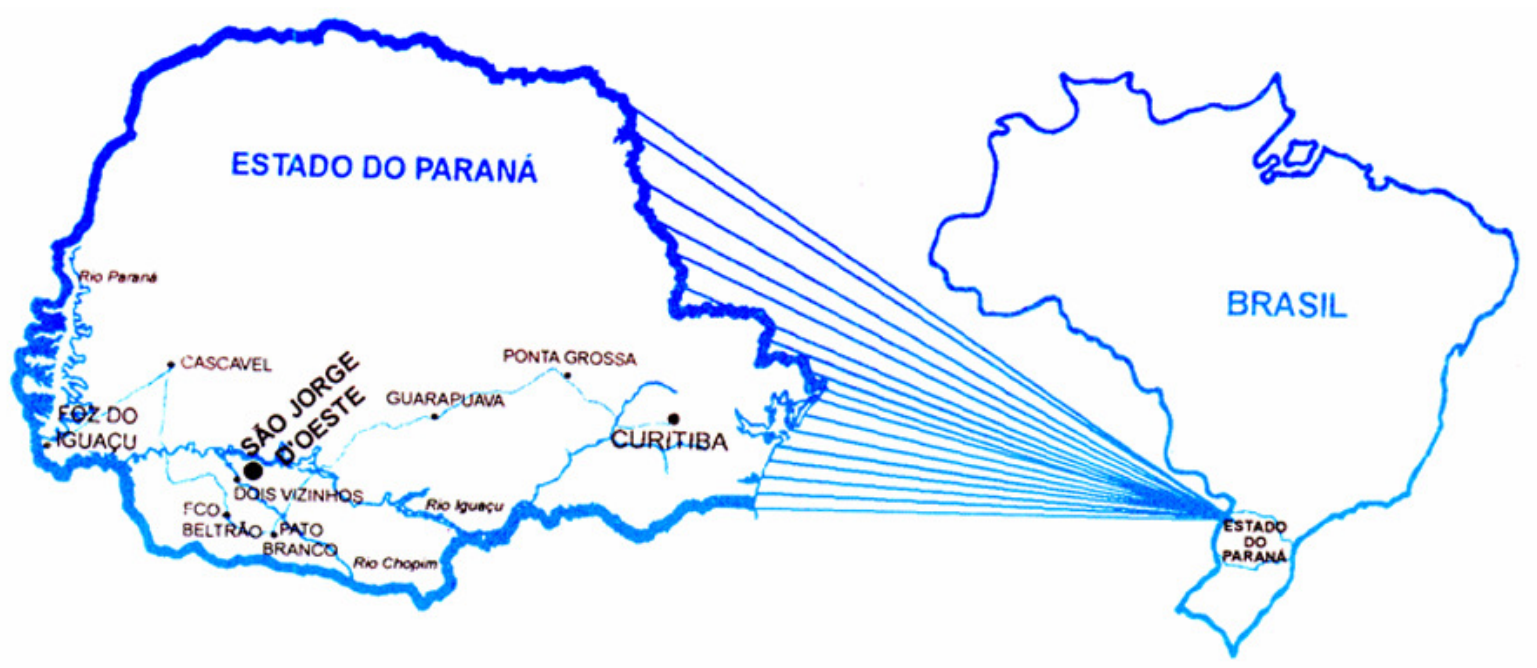

Fonte: Prefeitura Municipal de São Jorge do Oeste, 2010.

O reservatório da Usina Salto Osório, segundo dados da Prefeitura Municipal de São Jorge do Oeste (2010, p.06), está situado a uma distância de 23 km da cidade do município de São Jorge, no Distrito Lagos do Iguaçu. Surgiu com a construção da barragem da Usina Hidrelétrica de Salto Osório no Rio Iguaçu, obra empreendida pela Eletrosul Centrais Elétricas S. A., a partir de 1970. Em 1975, o lago ficou formado, cobrindo centenas de alqueires de áreas cultiváveis com 
pastagens e matas nativas. Em alguns locais do reservatório, a profundidade chega a 90 metros.

As autoridades municipais de São Jorge do Oeste, assim como os moradores próximos ao lago têm se esforçado em suas ações para desenvolver o turismo no reservatório da Usina Salto Osório, inclusive adotando o seguinte slogan: São Jorge do Oeste, terra dos lagos do Iguaçu. Atualmente, o lago dessa Usina torna-se o maior referencial para o município.

O Distrito Lagos do Iguaçu, conforme dados da Prefeitura Municipal de São Jorge do Oeste (2010, p.05), possui atualmente mais de 350 propriedades particulares no seu entorno, sendo que a grande maioria dos proprietários comprou o terreno e construiu casa para lazer dos familiares. Das casas existentes, apenas 112 são de padrão médio, sendo o restante de alto padrão. A maioria das casas é ocupada no período de verão e seus proprietários residem nos municípios da região, a exemplo de Pato Branco e Francisco Beltrão. As propriedades possuem trapiches de acesso ao lago, embarcações (barcos, lanchas e jet skı), ajardinamento, piscinas, em algumas, e muito conforto.

Nos últimos anos, foram construídas algumas casas especialmente para serem alugadas. Em época de temporada, mesmo a diária cobrada sendo bem próxima do que se paga para ficar numa casa do litoral paranaense (em torno de $R \$ 250$ ), todas são ocupadas.

Além dessas casas construídas especialmente para serem alugadas, ainda há àquelas que são construídas para fins de residência e são alugadas também para pessoas que desejam passar férias ou final de semana no local.

Há também famílias que residem no local e, muitas destas, prestam algum tipo de serviço para os turistas e para os proprietários das residência de veraneio, como limpeza das casas, piscinas e jardins; outros instalaram bares e mini-mercados com produtos de primeira necessidade; alguns vendem em sua própria residência massas, pães e leite direto aos turistas. Outros residentes construíram barracões para alugar aos turistas que desejam guardar suas embarcações e que não têm residência no local. 
A infraestrutura básica do Distrito Lago do Iguaçu é fornecida pela prefeitura municipal de São Jorge do Oeste. Boa parte das ruas recebeu calçamento e outras estão em processo de melhoria. Nesse local foi implantado posto policial que cuida da segurança pública e todas as casas e áreas de campings possuem energia elétrica. Contudo, não há sistema de abastecimento de água e coleta de esgoto. $\mathrm{A}$ água utilizada vem de poços artesianos e o esgoto vai para as fossas sépticas que, quando atingem a capacidade máxima de armazenamento, são coletadas por empresas particulares.

Quanto aos atrativos turísticos existentes na localidade do Distrito Lagos do Iguaçu a tabela 01 apresenta os principais citados pelos entrevistados.

TABELA 01 - Principais Atrativos turísticos do Distrito Lagos do Iguaçu

\begin{tabular}{|c|c|c|}
\hline Atrativos Turísticos & $\mathbf{N}^{\circ}$ Entrevistados & $\%$ \\
\hline $\begin{array}{l}\text { Lago da Usina Salto } \\
\text { Osório. }\end{array}$ & 7 & 70 \\
\hline $\begin{array}{l}\text { As praias artificiais e } \\
\text { áreas de campings. }\end{array}$ & 3 & 30 \\
\hline Total & 10 & 100 \\
\hline
\end{tabular}

Fonte: Pesquisa de campo, maio de 2010.

Como pode ser observado na tabela 01, o reservatório da Usina Salto Osório é o grande atrativo turístico do Distrito Lagos do Iguaçu e o elemento básico da atração turística desta localidade, tornando-se o maior referencial do próprio município. Dos 10 entrevistados, 70\% apontaram o reservatório como atrativo turístico principal da localidade.

As praias artificiais e as áreas de campings foram citadas por $30 \%$ dos entrevistados como atrativo principal. No local, há duas áreas de campings organizadas e mantidas por famílias pioneiras que ali residem, as quais contam com chalés, espaços arborizados, mesas para refeições, mesas de jogos, churrasqueiras, bar, água potável de poço artesiano, banheiros, trapiches para embarcações, posto telefônico, calçamentos e eletrificação. A visitação é aberta e no 
período de verão milhares de pessoas freqüentam os campings e margens da represa, principalmente as praias artificiais existentes no local.

Os turistas que chegam ao Lago do Iguaçu podem visitar a Gruta "Lagos do Iguaçu" existente às margens do reservatório e com acesso, após chegar no Distrito, tanto por água (com trapiche para embarque e desembarque) quanto por terra. $\mathrm{Na}$ gruta, conforme mostra a foto 01 , sempre há flores e velas acesas e recebe muitas visitas, especialmente nos finais de semanas e feriados.

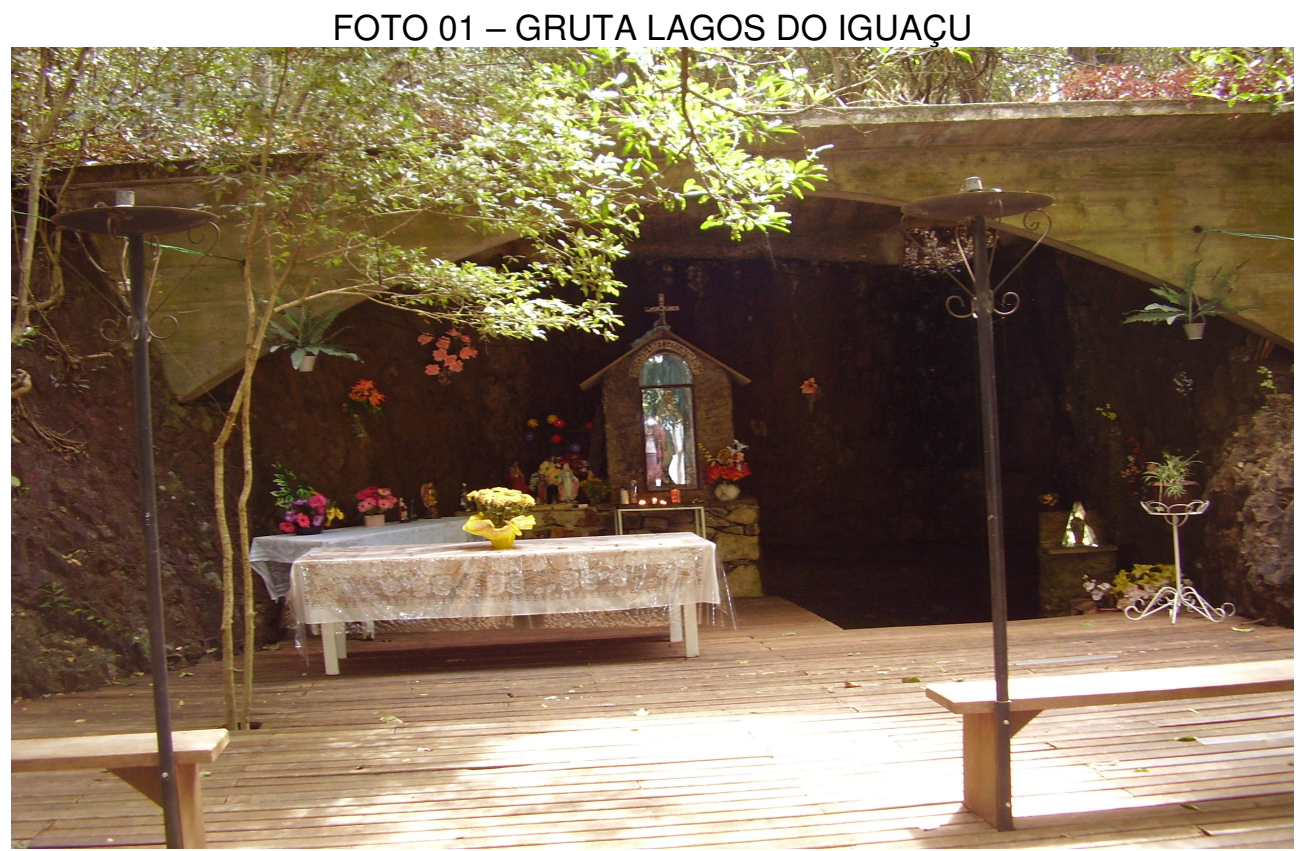

Fonte: MIGLIORINI, Sonia, janeiro de 2010.

Outro atrativo turístico existente no local, mas que não foi citado pelos entrevistados, é o moderno centro de convenções, foto 02 , localizado às margens do reservatório, com mais de 2.000 metros quadrados de área construída e um ajardinamento bem conservado. Em torno desse centro há uma área arborizada, com vista para o lago, possui mesas, bancos e energia elétrica. Neste espaço, são realizados eventos que atraem turistas de vários municípios da região Sudoeste. Além desses atrativos, há no local um clube dançante, cujos bailes são realizados em época de temporada. 


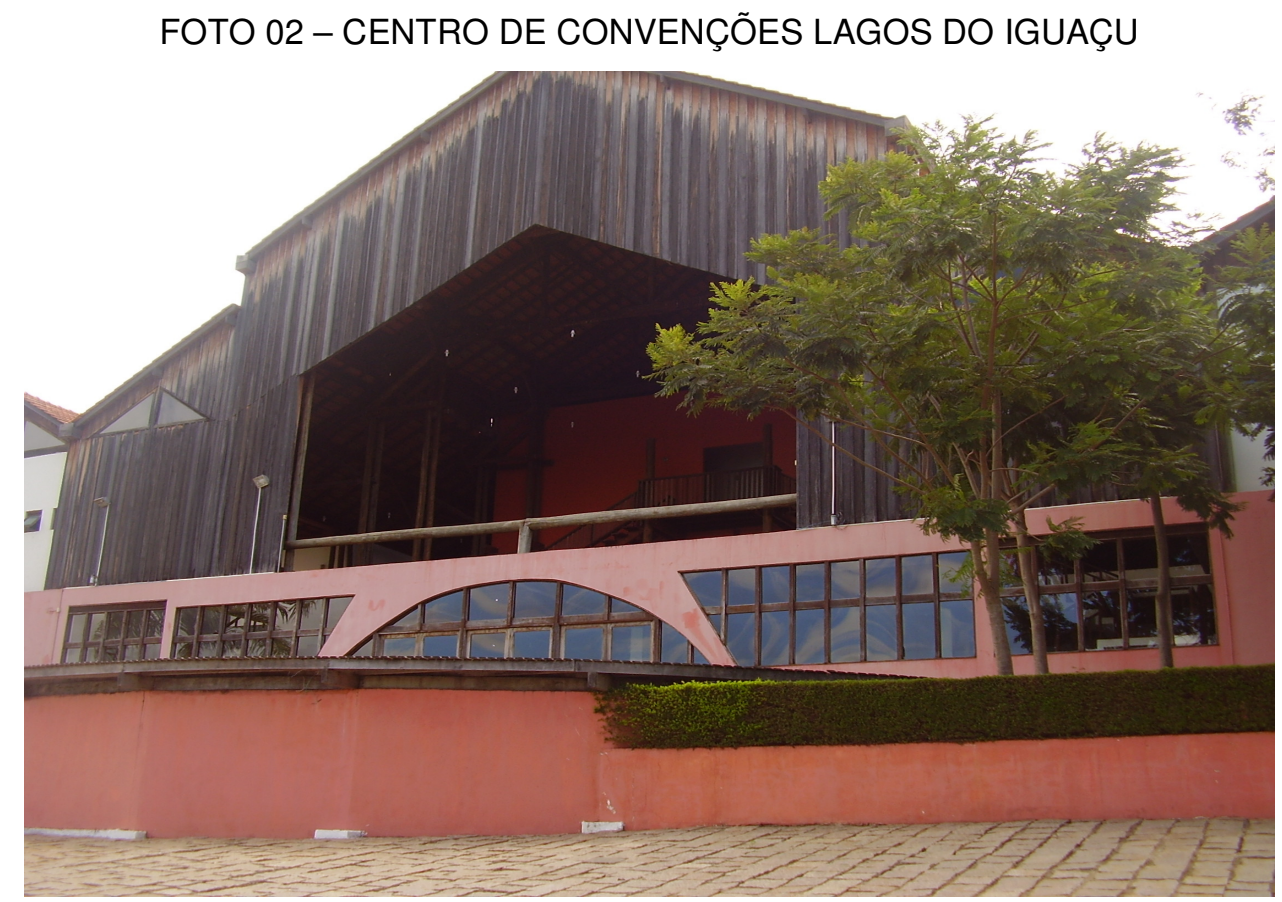

Fonte: MIGLIORINI, Sonia, janeiro de 2010.

Quanto às atividades recreativas praticadas no Distrito Lagos do Iguaçu, as aquáticas são predominantes, como se observa na tabela 02 :

TABELA 02 - Atividades Recreativas Praticadas no Distrito Lagos do Iguaçu

\begin{tabular}{|c|c|c|}
\hline Atividades Praticadas & $\mathrm{N}^{\circ}$ de Entrevistados & $\%$ \\
\hline Banho de sol e natação. & 8 & 26 \\
\hline $\begin{array}{l}\text { Passeio no reservatório } \\
\text { com embarcações a motor } \\
\text { (barcos, lanchas e Jet } \\
\text { Sky). } \\
\text { Pesca }\end{array}$ & 7 & 23 \\
\hline Caminhadas. & 5 & 16 \\
\hline $\begin{array}{l}\text { Jogo de futebol de campo } \\
\text { de salão. }\end{array}$ & 4 & 13 \\
\hline Total ${ }^{*}$ & 31 & 100 \\
\hline
\end{tabular}

Fonte: Pesquisa de campo, maio de 2010.

* O total de respostas é superior ao número da amostra porque o entrevistado poderia citar alternativa 
Das 31 respostas obtidas sobre as principais atividades recreativas desenvolvidas no distrito Lagos do Iguaçu 26\% (oito dos dez entrevistados) apontaram o banho de sol e a natação. Essas atividades, sem dúvida, são as mais praticadas pela população visitante. Já os passeios pelo reservatório com embarcações a motor foram citados por sete, dos dez entrevistados ( $23 \%$ das 31 respostas obtidas) como atividades recreativas principal. A pesca, citada igualmente por sete, dos dez entrevistados, corresponde como uma das atividades recreativas mais praticadas no reservatório da Usina Salto Osório.

Outras atividades recreativas importantes citadas pelos entrevistados, porém, não ligadas diretamente ao reservatório, são as caminhadas em torno do lago, citado por cinco dos dez entrevistados; e os jogos de futebol de campo e de salão apontados por $13 \%$ das 31 respostas obtidas.

A análise dos principais atrativos turísticos, assim como as atividades recreativas desenvolvidas no Distrito Lagos do Iguaçu, revela que o turismo empreendido gira em torno do reservatório da Usina, daí a importância de preservar a área. A seguir serão apresentados os impactos ambientais causados pelo turismo nesse local.

\section{IMPACTOS AMBIENTAIS GERADOS PELA ATIVIDADE TURÍSTICA NO RESERVATÓRIO DA USINA SALTO OSÓRIO}

Junto com o desenvolvimento do turismo, se não for bem planejado, muitas vezes, poderá ocorrer conseqüências negativas para o meio ambiente e a própria atividade turística. É relevante dizer que a atividade turística em áreas naturais vem crescendo nos últimos anos. Mas, na maioria dos casos, é preciso que ocorra um melhor planejamento das mesmas. É o caso do reservatório da Usina Salto Osório e do Distrito Lagos do Iguaçu, cujos impactos ambientais são inúmeros e caso não sejam corrigidos a tempo poderão causar prejuízos para o turismo local.

As entrevistas feitas com turistas no Distrito Lagos do Iguaçu, juntamente com as observações realizadas, revelaram que o desenvolvimento do turismo vem trazendo impactos ambientais no reservatório e no seu entorno, conforme observado na tabela 03. 
TABELA 03 - Impactos Ambientais Causados pela Atividade Turística no Reservatório da

\begin{tabular}{|c|c|c|}
\hline \\
\hline Impactos Ambientais & $\mathrm{N}^{\circ}$ Entrevistado & $\%$ \\
\hline Poluição da água devido ao lançamento de esgoto. & 9 & 32 \\
\hline $\begin{array}{l}\text { Degradação da mata ciliar e poluição das margens do } \\
\text { reservatório. }\end{array}$ & 7 & 26 \\
\hline $\begin{array}{l}\text { Poluição do ar devido ao mau cheiro do lixo acumulado na } \\
\text { beira das ruas. }\end{array}$ & 6 & 21 \\
\hline $\begin{array}{l}\text { Poluição da água por resíduos expelidos por embarcações } \\
\text { (graxas, óleos e gases) e por lixos lançados das } \\
\text { embarcações. }\end{array}$ & 6 & 21 \\
\hline Total $^{*}$ & 28 & 100 \\
\hline
\end{tabular}

Fonte: Pesquisa de campo, maio de 2010.

* O total de respostas é superior ao número da amostra porque o entrevistado poderia citar alternativa.

$\mathrm{Na}$ visão dos entrevistados, o maior impacto ambiental causado pelo desenvolvimento da atividade turística é a poluição da água do reservatório que é o principal atrativo turístico do Distrito Lagos do Iguaçu, bem como do município de São Jorge do Oeste e região. Dos 10 entrevistados, nove deles, no universo de $32 \%$ das 28 respostas, citaram o lançamento de esgoto sem tratamento no lago como o grande responsável pela poluição do reservatório.

Apesar das residências possuírem fossas sépticas, na maioria delas existe um encanamento saindo direto da fossa para o reservatório, favorecendo o escoamento do esgoto e sem nenhum tratamento prévio. Alguns moradores até tentaram mascarar a existência dessa tubulação, como é o caso de um proprietário que construiu uma capela bem próxima ao lago, exatamente por onde o esgoto passa.

Mesmo com a construção da capela, é visível o esgoto escorrendo no lago. Além disso, a área na qual o esgoto se mistura com a água cria limo verde. Esse esgoto lançado no lago se mistura com a água exatamente nas áreas que os turistas utilizam para banhos e pescarias.

Além do esgoto, existem os lixos e os resíduos lançados pelas embarcações. Foram destacados por seis, dos dez entrevistados, como sendo ambos os fatores que poluem a água do reservatório. Os passeios pelo lago é uma das atividades mais praticadas no local. No verão, é grande o número de barcos, lanchas e Jet ski que circulam pelo reservatório, os quais contribuem para a poluição da água já que 
lançam graxas, óleos e gases. Além disso, a queima de combustível, especialmente do Jet ski é elevada (em torno de 40 litros de gasolina por hora), segundo informou um proprietário, o que significa que as embarcações a motor poluem a água e o ar.

A degradação da mata ciliar e a poluição das margens do reservatório foram apontadas por sete dos dez entrevistados (universo de $26 \%$ das 28 respostas obtidas) como um dos maiores impactos ambientais causados pelo turismo no local. Para a construção das residências de veraneio, das áreas de camping e das praias artificiais, localizadas às margens do reservatório, destruíram a mata ciliar a fim de que o lago pudesse ser avistado das residências e das ruas.

Convém chamar a atenção que muitas residências existentes às margens do lago foram construídas encostadas no reservatório, o que significa que os proprietários não estavam preocupados em respeitar e preservar o meio ambiente, mas sim em usufruir o máximo deste local. Quase todos os proprietários construíram trapiches, ver foto 03 , em frente a sua residência, existindo grandes construções dentro do próprio reservatório.

\section{FOTO 03 - TRAPICHES CONSTRUÍDOS DENTRO DO LAGO EM FRENTES DE RESIDÊNCIAS}

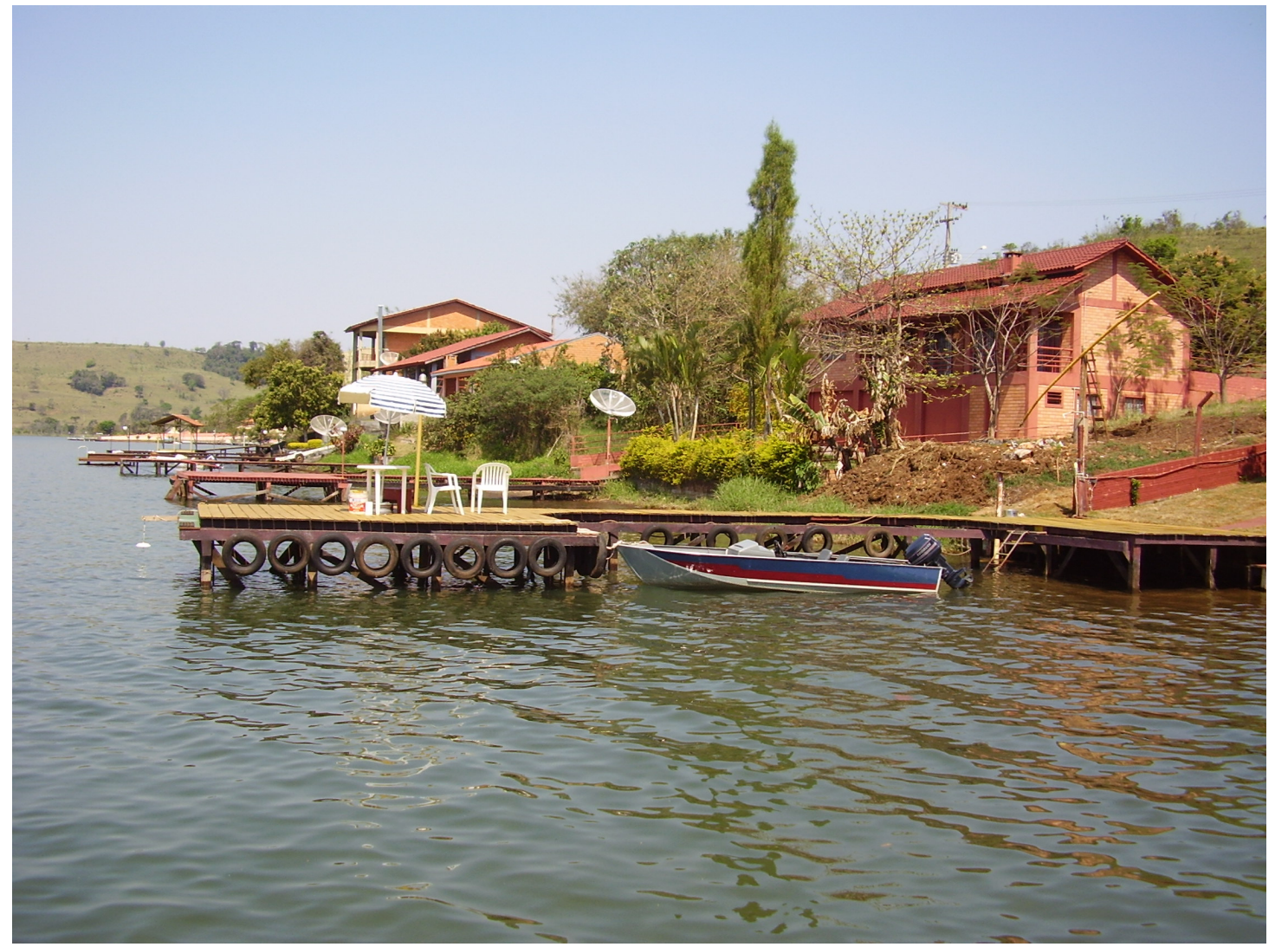

Fonte: MIGLIORINI, Sonia, janeiro de 2010. 
Dentro do lago, na parte que fica entre o trapiche e a margem do reservatório, em frente a uma residência, existe a construção de um piso de concreto feito com o objetivo de cobrir a lama do fundo da água e tornar mais agradável a entrada no lago, o que demonstra total despreocupação com a preservação do reservatório.

A falta de uma legislação clara e punitiva, sobretudo, de uma fiscalização rigorosa que exija o cumprimento da lei permite que os investidores abusem no uso desse lugar. Parece que o poder aquisitivo sobrepõe a questão ambiental e muitas das construções não respeitam qualquer legislação ambiental, sendo visíveis os impactos deixados por elas.

A grande quantidade de lixo gerado pelos turistas que visitam o local é outro fator poluente e citado por seis, dos dez entrevistados como maior causador de impactos ambientais. Em épocas de temporada, segundo dados da prefeitura municipal de São Jorge do Oeste, a população visitante do Distrito Lagos do Iguaçu chega a 5.000 pessoas. Junto com esta concentração de turistas vem também a sujeira e o mau cheiro advindos da enorme quantidade de lixo depositado nas lixeiras localizadas no entorno do lago e à beira das ruas, o que torna desagradável o passeio no local.

A prefeitura municipal de São Jorge do Oeste faz a coleta do lixo somente uma vez por semana nesse Distrito, logo, é insuficiente nas épocas de temporada, causando o acúmulo de muito lixo, foto 04 , e devido ao tempo de permanência nas lixeiras exala mau cheiro, deixando os visitantes incomodados.

Como foi possível observar, no Distrito Lagos do Iguaçu o crescimento dos investimentos de capital, bem como o aumento do fluxo de pessoas, principalmente no verão, é visível. Contudo, junto com o desenvolvimento do turismo vieram impactos ambientais, tais como a poluição do reservatório e a retirada das matas ciliares. 
FOTO 04 - LIXO ACUMULADO À BEIRA DAS RUAS NO DISTRITO LAGOS DO IGUAÇU

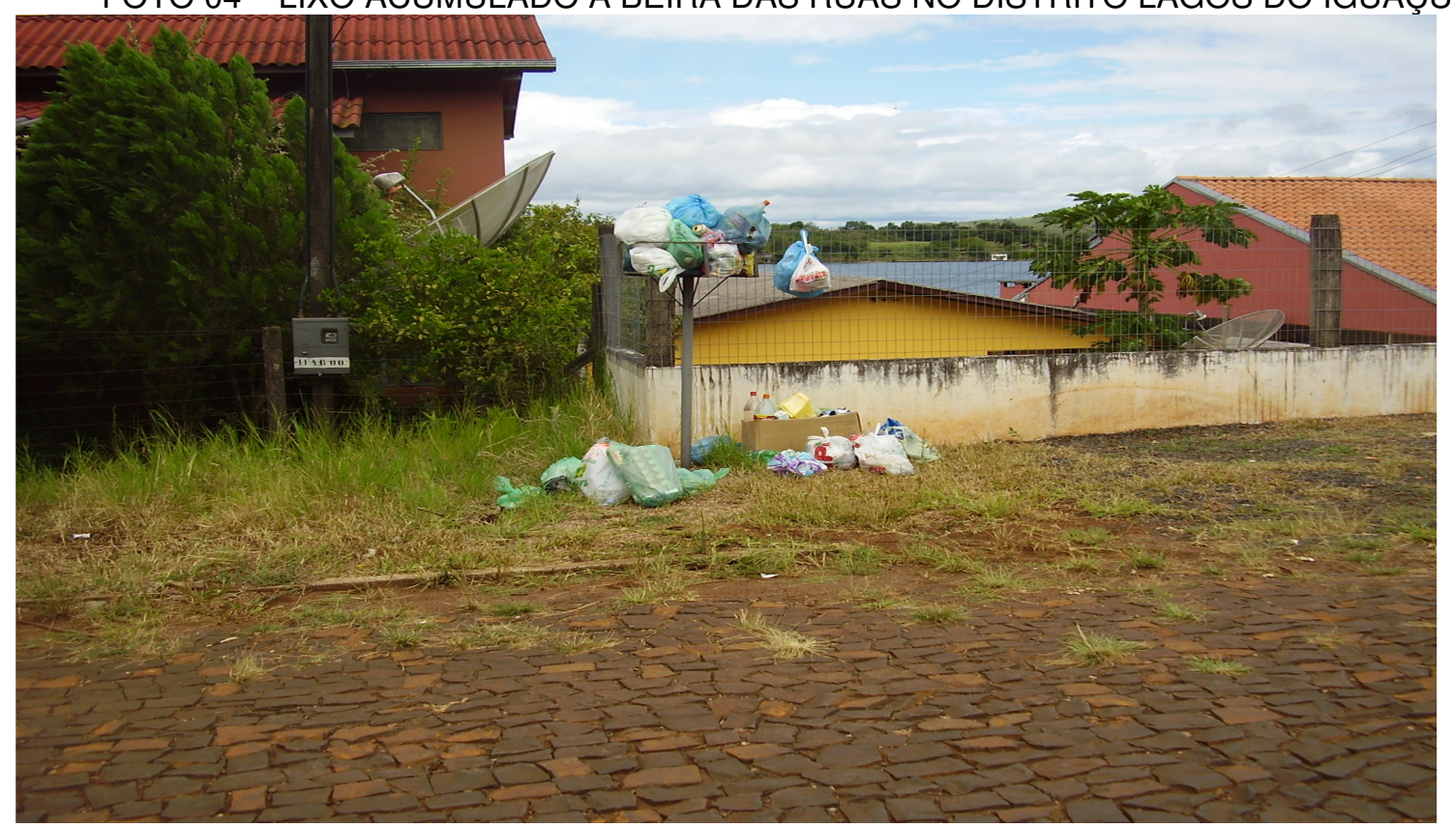

Fonte: MIGLIORINI, Sonia, janeiro de 2010.

\section{CONSIDERAÇÕES FINAIS}

Os resultados da pesquisa revelaram que o reservatório da Usina Salto Osório, no Distrito Lagos do Iguaçu do município de São Jorge do Oeste Paraná, é o principal atrativo turístico dessa região. No que se refere às atividades recreativas realizadas pelos turistas nesse reservatório, sobressaem àquelas ligadas aos recursos hídricos tais como: natação, passeios nas embarcações a motor, pesca e banho de sol.

Vale mencionar que o entorno do Lago da usina Salto Osório nos últimos anos vem se equipando com a infraestrutura básica necessária para a visitação turística com a instalação de energia elétrica, postos telefônicos e calçamentos. Com isso o investimento privado no local cresceu fortemente, bem como a especulação imobiliária. Contudo, há espaços para todas as classes sociais, uma vez que a média e alta construíram suas próprias residências entorno do lago ou alugam casas para turistas passarem férias, enquanto às classes mais baixas ocupam as praias artificiais e áreas de camping.

À guisa de conclusão, o turismo no reservatório da Usina Salto Osório é uma das alternativas para o desenvolvimento do município São Jorge do Oeste e outros 
adjacentes, mas é preciso considerar os impactos ambientais trazidos, desde o lançamento de resíduos das embarcações, destruição da mata ciliar, lançamento de esgoto no lago e lixo no seu entorno, o que deixa claro a necessidade de um planejamento melhor da atividade turística nesse local.

Ou seja, a poluição da água do lago e do seu entorno pelos turistas traz prejuízos não somente para a comunidade local, beneficiada com o reservatório, como põe em risco a própria atividade turística. Se o problema do lixo, esgoto, e da poluição do reservatório não forem solucionados, certamente o turismo ficará comprometido.

Portanto, é preciso que haja um planejamento mais intenso e eficaz na área estudada, de modo que a atividade turística continue beneficiando a comunidade que habita essa região, sendo mais uma alternativa para o desenvolvimento do município de São Jorge do Oeste e de toda a região Sudoeste do Paraná. Todavia, torna-se necessário pensar na preservação dos recursos naturais existentes, especialmente dos reservatórios das usinas hidrelétricas aqui citadas, aliando-se a uma proposta de consciência ambiental no tocante ao conjunto de atrativos existentes.

\section{REFERÊNCIAS}

ALMEIDA, Roberto Alves de ; VIANA, A. N. C. ; ALVES, A. S. V. . Impacto do deplecionamento de reservatórios de regularização no setor de turismo em municípios lindeiros: o caso do reservatório de Furnas. In: XVII Simpósio Brasileiro de Recursos Hídricos, 2007, São Paulo. Disponível em: <http://www.abrc.org.br>. Acesso em: 25/10/2010.

ANA, Agência Nacional de Águas. Caderno de Recursos Hídricos: 0 turismo e o lazer e sua interface com o setor de recursos hídricos. Brasília, 2005.

BAHL, Miguel. Legados Étnicos \& Ofertas Turísticas. Curitiba: Juruá, 2004.

BENI, Mário Carlos. Análise estrutural do turismo. 2ª ed. São Paulo: Aleph, 1998.

BARRETTO, Margarita A. N. Planejamento e Organização em Turismo. Campinas, SP: Papirus, 1991.

BARRETO, M. Manual de iniciação ao estudo do turismo. Campinas: Papirus, 1995.

BELTRÃO, Otto di. Turismo: A indústria do século 21. Lorena, SP: Stiliano, 1999. 
COSTA, Maria A. F; RIBEIRO, Willame O. e TAVARES Maria G. C. O Turismo Enquanto Espaço de Análise Geográfica: Três perspectivas de abordagem. Revista MERCATOR, Ceará, n. 06, p. 33-42, 2004.

DE LA TORRE, Oscar. El Turismo: Fenômeno social. México: Fondo de cultura econômica, 1994.

DIAS, R. e AGUIAR. Fundamentos do Turismo: Conceitos, normas e definição. Campinas, SP: Editora Alínea, 2002.

IBGE, Instituto Brasileiro de Geografia e Estatística. Cidades@: Município de São Jorge do Oeste. 2010. Disponível em: <http://www.ibge.com.br>. Acesso em: 22/07/10.

LEI n. 9.433/97. Da Política Nacional de Recursos Hídricos. Disponível em: <http://www.lei.adv.br/9433-97.htm>. Acesso em: 22/07/10.

MESQUITA, Érika. Um olhar sócio-geográfico sobre o turismo. In: Associação Nacional de Pós-Graduação e Pesquisa em Ambiente e Sociedade, II, 2004, São Paulo. Anais eletrônicos. Disponível em: < http://www.anpps.org.br>. Acesso em: 24/10/2010

OLIVEIRA, Antonio Pereira. Turismo e Desenvolvimento: Planejamento e organização. 2 ed. São Paulo: Atlas, 2000.

Prefeitura Municipal de São Jorge do Oeste. Turismo: Lagos do Iguaçu. 2010.

Disponível em: <http://www.pmsjorge.com.br/turismo>. Acesso em: 18/07/2010.

Prefeitura Municipal de São Jorge do Oeste. História e Localização do Município. Disponível em: <http://www.pmsjorge.com.br/historia.htm>. Acesso em: 16/09/10.

RODRIGUES, Adyr, B. Turismo local: oportunidade para inserção. In: RODRIGUES, A. B. (Org.) Turismo e desenvolvimento local. São Paulo: Hucitec, 1997.

RODRIGUES, Adyr B.. Turismo e Espaço: rumo a um conhecimento transdiciplinar. São Paulo: Hubicitec, 2001a.

RODRIGUES, Adyr B. (Org.). Turismo e Geografia: reflexões teóricas e enfoques regionais. 3 ed. São Paulo: Hucitec, 2001b.

PERTILLE E LANZER. Turismo em reservatórios de hidrelétricas - uma reflexão sobre o múltiplo uso e os possíveis impactos ambientais. In: Seminário de Pesquisa em Turismo do MERCOSUL - IV Simin TUR, 2006, Caxias do Sul. Disponível em: <http://www.ucs.br >. Acesso em: 24/10/2010.

RUSCHMANN, Doris, SOLHA, Karina Toledo (orgs.). Planejamento turístico. São Paulo: Manole, 2006.

SWARBROOKE, John. Conceitos e impacto ambiental. $3^{\underline{a}}$ ed. (trad. Margarete dias Pulido). São Paulo: Aleph, v.1, 2000. 
TARLOMBANI DA SILVEIRA, Marcos A.. Turismo, Políticas de Ordenamento Territorial e Desenvolvimento: Um foco no estado do Paraná no contexto regional. São Paulo: USP, 2002. Tese de Doutorado.

VILAS BOAS, C. L. de. Uso múltiplo de reservatórios. In: Seminário da Engenharia Comemorativo ao Dia Mundial da Água, Goiânia, 2006. Disponível em: <http://www.cprm.gov.br >. Acesso em: 25/10/2010.

(Recebido em maio/2010. Aceito em outubro/2010) 